\title{
Effect of Temperature on Anthocyanin Synthesis and Ethylene Production in the Fruit of Early- and Medium- maturing Apple Cultivars during Ripening Stages
}

\author{
Chikako Honda ${ }^{1}$ \\ NARO Institute of Fruit Tree Science, Morioka, Iwate 020-0123, Japan
}

Hideo Bessho

NARO Institute of Fruit Tree Science, Tsukuba, Ibaraki 305-8605, Japan

Mari Murai

NARO Tohoku Agricultural Research Center, Morioka, Iwate 020-0198, Japan

Hiroshi Iwanami, Shigeki Moriya, Kazuyuki Abe, Masato Wada, and Yuki Moriya-Tanaka NARO Institute of Fruit Tree Science, Morioka, Iwate 020-0123, Japan

\author{
Hiroko Hayama and Miho Tatsuki \\ NARO Institute of Fruit Tree Science, Tsukuba, Ibaraki 305-8605, Japan \\ Additional index words. anthocyanin, apple, ethylene, fruit color, ripening, temperature
}

Abstract. The objective of this study was to investigate the effects of temperature treatments on anthocyanin accumulation and ethylene production in the fruit of early- and medium-maturing cultivars that were harvested early during fruit ripening. We first investigated the effects of various temperature treatments on anthocyanin accumulation in detached apples of 'Tsugaru', 'Tsugaru Hime', 'Akane' and 'Akibae' using an incubator. Three years of experiments demonstrated that at harvest, the lower-temperature treatments induced anthocyanin accumulation in 'Tsugaru', 'Tsugaru Hime', and 'Akibae' fruits, whereas the increases in anthocyanin accumulation under the $25^{\circ} \mathrm{C}$ treatment were similar to those under the 15 and $20{ }^{\circ} \mathrm{C}$ treatments in 'Akane' fruit. The rate of ethylene production did not increase substantially during the temperature treatments in any of the four cultivars, except after the treatments of 'Tsugaru' fruit at harvest. The inhibition of ethylene action by the application of 1-methylcyclopropene (1-MCP) to detached fruits at harvest suppressed anthocyanin development under 15 and $20{ }^{\circ} \mathrm{C}$ temperature treatments in 'Tsugaru', 'Tsugaru Hime', and 'Akibae', but not in 'Akane'. In the second experiment, we investigated changes in the anthocyanin concentration in attached fruit of 'Misuzu Tsugaru' under different temperature conditions in a greenhouse. At harvest, the anthocyanin concentration in fruit under the hotter climatic condition $\left(29^{\circ} \mathrm{C} 12\right.$ hours $/ 19^{\circ} \mathrm{C} 12$ hours) was lower than that under the control condition $\left(25^{\circ} \mathrm{C}\right.$ 12 hours $/ 15{ }^{\circ} \mathrm{C} 12$ hours). During the last week before harvest, anthocyanin development proceeded rapidly in fruit skin not only under the control condition, but also under the hotter climatic condition. The rapid accumulation of anthocyanin in the fruit skin of 'Misuzu Tsugaru' at harvest under a relatively high temperature $\left(25^{\circ} \mathrm{C}\right)$ condition was confirmed by the experiment using an incubator. At harvest, the maximum level of ethylene production in fruits sampled from trees grown under the hotter climatic condition was 9-fold higher than that in fruits from trees grown under the control condition. These results indicate that the comparison of pigmentation potential after the 15 or $25{ }^{\circ} \mathrm{C}$ treatments using detached fruit was effective for estimating anthocyanin accumulation in fruit skins under hotter climatic conditions in early- and medium-maturing cultivars that were harvested early and that a hotter climatic condition during ripening increased ethylene production in apple fruit after harvest.

Received for publication 14 July 2014. Accepted for publication 12 Oct. 2014.

${ }^{1}$ To whom reprint requests should be addressed; e-mail hondac@affrc.go.jp. apple fruit skin is of interest because the red coloration of apples is an important factor in market acceptance. The effect of export on the potential for anthocyanin synthesis/ accumulation has been widely reported in red sports of the cultivars Gala, Red Delicious, and Fuji, among other important cultivars (Iglesias et al., 1999a, 2012; Iglesias and Echeverría, 2009). Anthocyanin synthesis in the fruit skin of red cultivars is affected by external biotic and abiotic factors, including nutrients, water stress, wounding, light, and temperature (Ubi, 2004). The effect of temperature on anthocyanin accumulation is of particular interest because hot climatic conditions result in low pigmentation in apple fruit (Lin-Wang et al., 2011; Palmer et al., 2012), which reduces the market value. Higher temperatures repress not only the expression levels of anthocyanin biosynthetic genes (Ubi et al., 2006) and MYB transcription factor genes (Ban et al., 2007; Lin-Wang et al., 2011; Palmer et al., 2012), but also the activity of phenylalanine ammonia-lyase, a biosynthetic enzyme (Iglesias et al., 1999b), consequently decreasing anthocyanin biosynthesis in apple fruit skin. On a practical note, it is important to understand the temperature dependency of anthocyanin accumulation in apple fruit to achieve effective fruit color management such as through evaporation cooling (Iglesias et al., 2002, 2005). Therefore, optimal temperatures for fruit pigmentation have been reported for various apple cultivars using detached fruit (Arakawa, 1991; Curry, 1997; Faragher, 1983; Marais et al., 2001). However, because the experimental conditions differed among the respective reports, comparing their results is difficult.

Ethylene is a key plant hormone involved in fruit ripening in apples (Saure, 1990). Whale and Singh (2007) reported that ethylene appeared to be a key factor regulating anthocyanin development in 'Pink Lady' fruit because ethylene production was significantly correlated with anthocyanin biosynthesis, but not with the accumulation of other flavonoids. Exogenous ethylene application promotes anthocyanin synthesis in fruit skin during the ripening stage (Larrigaudiere et al., 1996; Li et al., 2002). Recently, Johnston et al. (2009) showed that antisense suppression of $M d A C O 1$, an ethylene biosynthetic gene, decreased the ethylene concentration in the core cavity of fruit and led to poor red pigmentation in transgenic 'Royal Gala' apples. This reveals that ethylene production is essential for full anthocyanin accumulation in the apple fruit skin during ripening. Like anthocyanin synthesis, ethylene production in apple fruit is also influenced by temperature conditions. Tromp (1997) demonstrated that low-temperature treatment $\left(16^{\circ} \mathrm{C}\right)$ during a 6-week period after bloom repressed ethylene production in 'Elstar' fruit until a later stage, and cold storage of 'Tsugaru' fruit after harvest suppressed ethylene production (Tatsuki et al., 2011).

Genetic and molecular studies indicate that ethylene receptors are negative regulators of ethylene-dependent responses (Hua 
and Meyerowitz, 1998). The compound $1-\mathrm{MCP}$ is thought to inhibit the perception of ethylene by competing for ethylene receptors in fruit (Blankenship and Dole, 2003), and its application to fruit slows ethylene-dependent responses, including ethylene evolution (Tatsuki et al., 2011). Several studies have investigated the effects of the inhibition of ethylene action in apples through the preharvest application of 1-MCP, including those on shelf life, ethylene evolution, and red skin color. Elfving et al. (2007) showed that the application of 1-MCP to 'Scarletspur Delicious' and 'Cameo' apple trees at 1 to 4 weeks before harvest (WBH) had little effect on skin color development. Yuan and $\mathrm{Li}$ (2008) reported that the application of 1-MCP to a 'Delicious' apple tree at 15 and $7 \mathrm{~d}$ before harvest did not affect the red coloration of the fruit. It is possible that the roles of ethylene action in anthocyanin accumulation differ among cultivars.

Anthocyanin accumulation in the fruit skin of four cultivars (Tsugaru, Tsugaru Hime, Akane, and Akibae) is susceptible to the effect of hot climatic conditions because their fruits are harvested in early autumn. In this study, we investigated the effect of temperature on anthocyanin accumulation in four cultivars of detached apples during ripening. The first experiment conducted in 2008-10 involved placing detached apples of the cultivars Tsugaru, Tsugaru Hime, Akane, and Akibae in an incubator. We measured the rates of ethylene production and anthocyanin accumulation at harvest in fruits of these cultivars to which 1-MCP had been applied to assess the effect of ethylene inhibition on the strength of pigmentation. Second, we examined changes in anthocyanin accumulation and ethylene generation in the fruit of potted 'Misuzu Tsugaru', a red sport of 'Tsugaru', under different climatic conditions in a greenhouse.

\section{Materials and Methods}

Plant materials. Apple trees (Malus $\times$ domesitca Borkh.) were grown in an orchard at the NARO Institute of Fruit Tree Science, Morioka, Japan. Morioka, with an average annual temperature of $10.2{ }^{\circ} \mathrm{C}$, is a suitable area for apple production, particularly in terms of the temperature during fruit pigmentation. Two experiments were conducted to investigate the effect of temperature on anthocyanin accumulation in apple fruit. The first experiment involved an incubator and 'Tsugaru', 'Tsugaru Hime', 'Akane', and 'Akibae' apples, harvested from 2008 to 2010. In 2008, 2009 , and 2010 , the full bloom date was $\approx 4,9$, and 16 May, respectively. The second experiment required the use of a greenhouse and involved 'Misuzu Tsugaru' apple trees. All cultivars were grafted onto JM7 rootstock (Soejima et al., 1998) and trained as free spindle. The parentage, tree age, harvest date, and fruit qualities at commercial harvest for the cultivars are listed in Table 1.

Temperature treatment of detached apples. The temperature treatments in the first experiment were conducted essentially according to the methods of Arakawa (1991). Fruits were bagged in single-layer paper bags for 2 months before commercial harvest to partially shade them from sunlight. Bagged fruits were sampled 2 and 4 WBH and at harvest. After the bags were removed, the fruits were placed in incubators set at $15,20,25$, and $30^{\circ} \mathrm{C}$, respectively, with white and ultraviolet-B light provided by fluorescent tubes and left for $48 \mathrm{~h}$. The temperature treatment period in Arakawa's report was $96 \mathrm{~h}$, but we used a 48 -h period in this study because the anthocyanin concentrations in fruit skins after $48 \mathrm{~h}$ are proportional to those after $96 \mathrm{~h}$ in a number of cultivars (Bessho, unpublished data). A total of six to 10 fruits from each cultivar were used for each temperature treatment, and their anthocyanin concentrations were measured. Attached fruits that were not bagged under field conditions were sampled concurrently for anthocyanin analysis.

1-MCP treatment. Bagged fruits of each cultivar were harvested at commercial maturity in 2011. On the day of harvest, after the paper bags were removed, $\approx 36$ fruits were placed in a $117-\mathrm{L}$ plastic container containing 1 ppm 1-MCP (SmartFresh ${ }^{\mathrm{TM}}$; AgroFresh Inc., Springhouse, PA) at room temperature $\left(\approx 22^{\circ} \mathrm{C}\right)$ for $16 \mathrm{~h}$. These fruits were removed from the container $1 \mathrm{~d}$ after harvest (DAH), stored at room temperature overnight, and subjected to ethylene analysis and temperature treatments using an incubator as described previously at $2 \mathrm{DAH}$. Untreated fruits were placed at room temperature after harvest and a proportion was subjected to temperature treatment at $2 \mathrm{DAH}$. The rates of ethylene production in 1-MCP-untreated and -treated fruits were measured at 0,2, and 4 DAH. An anthocyanin analysis was conducted at 2 and 4 DAH.

Temperature treatment of potted trees. In the second experiment, two greenhouses located at the NARO Tohoku Agricultural Research Center were used to create control $\left(25{ }^{\circ} \mathrm{C} 12 \mathrm{~h} / 15{ }^{\circ} \mathrm{C} 12 \mathrm{~h}\right)$ and hotter climatic conditions $\left(29^{\circ} \mathrm{C} 12 \mathrm{~h} / 19^{\circ} \mathrm{C} 12 \mathrm{~h}\right)$. We performed the preliminary experiment under the control $\left(25^{\circ} \mathrm{C} 12 \mathrm{~h} / 15^{\circ} \mathrm{C} 12 \mathrm{~h}\right)$ and hotter climatic conditions $\left(30^{\circ} \mathrm{C} 12 \mathrm{~h} / 20^{\circ} \mathrm{C} 12 \mathrm{~h}\right)$ in 2008 and confirmed that a $5{ }^{\circ} \mathrm{C}$ increase in temperature suppressed anthocyanin accumulation in the fruit skin of 'Misuzu Tsugaru' in the greenhouse (data not shown). Therefore, the temperature difference was set at $4{ }^{\circ} \mathrm{C}$ $\left(25^{\circ} \mathrm{C} 12 \mathrm{~h} / 15^{\circ} \mathrm{C} 12 \mathrm{~h}\right.$ as the control condition and $29{ }^{\circ} \mathrm{C} 12 \mathrm{~h} / 19{ }^{\circ} \mathrm{C} 12 \mathrm{~h}$ as the hotter climatic condition) in 2009. We set the duration of daily temperature variation as $12 \mathrm{~h}$; the daytime (0600 to $1800 \mathrm{HR}$ ) temperature was maintained at $25^{\circ} \mathrm{C}$ and the nighttime ( 1800 to $0600 \mathrm{HR}$ ) temperature was maintained at $15^{\circ} \mathrm{C}$ for the control condition. Six potted 'Misuzu Tsugaru' apple trees were grown in a field until $5 \mathrm{WBH}$. Among them, two single-tree replicates were performed in each greenhouse at $5 \mathrm{WBH}$ and grown under natural light conditions until harvest. The remaining two potted trees were grown in the field until harvest. Attached fruit on the potted trees were not bagged during the experiment. Fruits were collected at four points in time $(1,3$, and 5 WBH and at harvest) for anthocyanin and ethylene analyses.

Anthocyanin and ethylene analyses. For the anthocyanin analyses, four disks $\left(0.64-\mathrm{cm}^{2} /\right.$ disk $)$ were cut from the upper portion of each fruit with a cork borer and soaked in 10-mL hydrochloric acid/methanol $(1: 99, \mathrm{v} / \mathrm{v})$ at $4{ }^{\circ} \mathrm{C}$ overnight. The absorbance of each extract at $530 \mathrm{~nm}$ was measured with a spectrophotometer (ultraviolet-1600; Shimadzu, Kyoto, Japan), and anthocyanin concentrations were calculated using a molar extinction coefficient of $3.43 \times 10^{4}$ (Chalmers et al., 1973). For the ethylene analyses, whole apples were placed in a 1.2-L glass container equipped with a septum at room temperature $\left(\approx 22^{\circ} \mathrm{C}\right)$ for $30 \mathrm{~min}$, and $1 \mathrm{~mL}$ of head-space gas was sampled using a syringe. The ethylene concentration was measured by gas chromatography (GC-201; Shimadzu).

\section{Results}

Effect of temperature on anthocyanin accumulation in detached apples. Temperature treatments were conducted at three points in time during fruit ripening to measure the potential ability to synthesize anthocyanin in the fruit skins of the early- and medium-maturing cultivars Tsugaru, Tsugaru Hime, Akane, and Akibae. Because the pattern of anthocyanin development in each cultivar was similar in 2008, 2009, and 2010 , the results are shown as the mean of the data from all 3 years (Fig. 1).

In the fruit of 'Tsugaru', a major earlymaturing cultivar in Japan, anthocyanin accumulation proceeded under the 15 and $20{ }^{\circ} \mathrm{C}$ treatments at the respective time points, and the maximum pigmentation potential was 5.9 $\mu \mathrm{g} \cdot \mathrm{cm}^{-2}$ in the $15^{\circ} \mathrm{C}$ treatment at harvest (Fig. 1A). The pigmentation potential in the $25^{\circ} \mathrm{C}$ treatment was not found at 4 and $2 \mathrm{WBH}$ but at harvest. The fruit of 'Tsugaru Hime', a red sport of 'Tsugaru', showed a similar pattern (Fig. 1B), except that at harvest the pigmentation potential in the 15,20 , and $25{ }^{\circ} \mathrm{C}$ treatments at harvest was more than 2-fold higher than that of 'Tsugaru', and the maximum pigmentation potential was found in the $15{ }^{\circ} \mathrm{C}$ treatment at harvest $\left(12.3 \mu \mathrm{g} \cdot \mathrm{cm}^{-2}\right)$. The attached fruit of 'Tsugaru Hime' accumulated 2-fold higher anthocyanin levels $\left(76.4 \mu \mathrm{g} \cdot \mathrm{cm}^{-2}\right)$ at harvest than did 'Tsugaru' $\left(37.6 \mu \mathrm{g} \cdot \mathrm{cm}^{-2}\right)$.

In 'Akane' fruit, the pigmentation potential under the 15,20 , and $25{ }^{\circ} \mathrm{C}$ conditions was observed during fruit ripening (Fig. 1C). At $2 \mathrm{WBH}$, the pigmentation potential in the $25{ }^{\circ} \mathrm{C}$ treatment reached the same level as that in the $15^{\circ} \mathrm{C}$ treatment. At harvest, there was no significant difference among the pigmentation potential in the 15,20 , and $25^{\circ} \mathrm{C}$ treatment groups. The maximum pigmentation potential of 'Akane' fruit was found in the $25^{\circ} \mathrm{C}$ treatment at harvest $\left(15.1 \mu \mathrm{g} \cdot \mathrm{cm}^{-2}\right)$. The final anthocyanin concentration in the attached fruit of 'Akane' was $125.5 \mu \mathrm{g} \cdot \mathrm{cm}^{-2}$. 


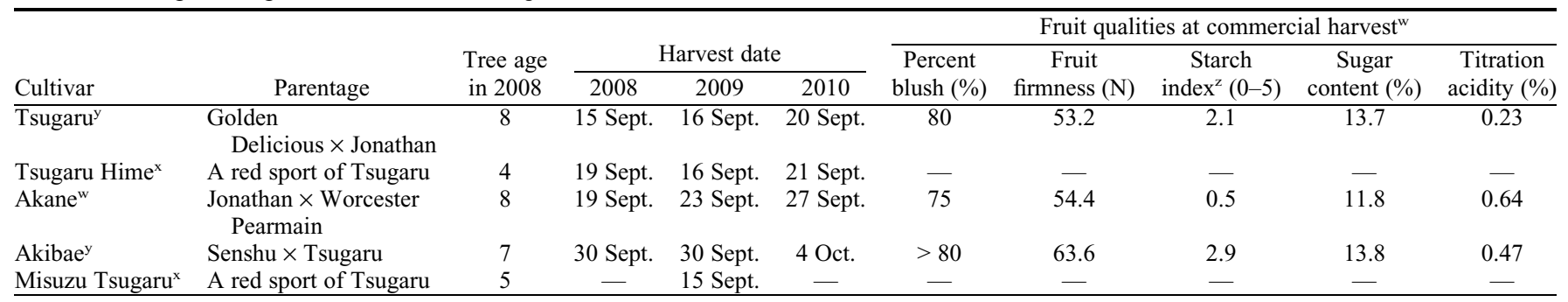

${ }^{2}$ The starch index ranges from 0 to 5 . A lower number means less intense staining of starch by iodine.

${ }^{y}$ The fruit quality values are the means from 2008 to 2010.

${ }^{x}$ The fruit qualities of red sports of 'Tsugaru' were similar to those of 'Tsugaru'.

${ }^{\text {w}}$ The values given for various fruit qualities, except percent blush, are the mean values for 2004 and 2005 . The value given for percent blush is the mean of the values from 2010 and 2011.
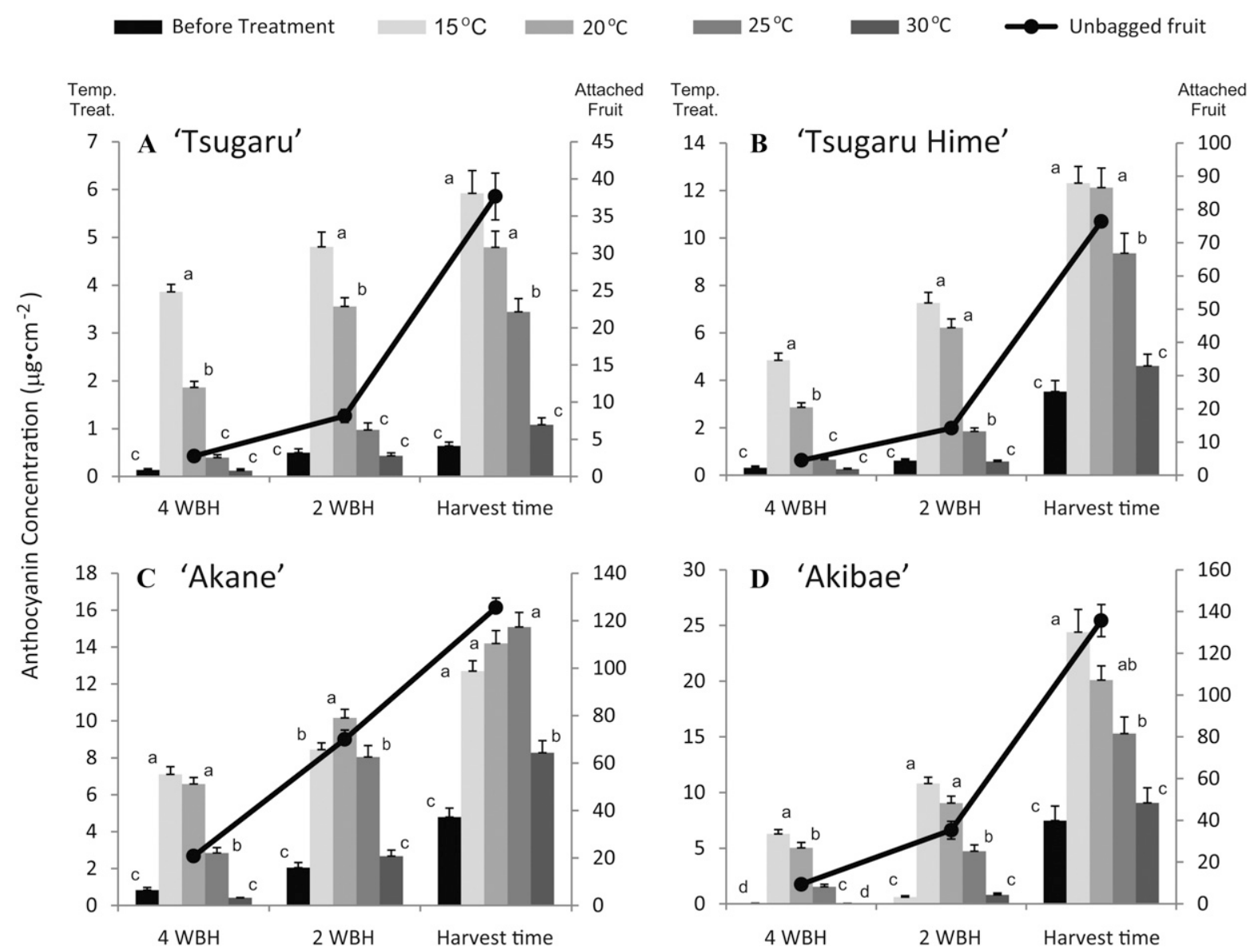

Fig. 1. Effect of temperature treatment on the induction of anthocyanin synthesis in early- and medium-maturing apple fruits during the ripening period. The temperature treatments were conducted by keeping detached fruits at $15,20,25$, or $30^{\circ} \mathrm{C}$ for $48 \mathrm{~h}$. The mean was calculated using the data from 2008 to 2010 . The left vertical axis is used to describe anthocyanin concentrations before and after the temperature treatments in detached fruit. The right vertical axis shows the anthocyanin concentrations in attached fruits of: (A) 'Tsugaru', (B) 'Tsugaru Hime', (C) 'Akane', and (D) 'Akibae'. Each bar or symbol represents the mean of 24 to 30 replicates; error bars indicate $\pm 1 \mathrm{SE}$. Error bars are not shown when SE was smaller than the symbol (black circle) for the anthocyanin concentration. Different letters indicate significant differences between temperature treatments within the same day at $P<0.05$, as determined using Tukey-Kramer tests.

In the fruit of 'Akibae', the pigmentation potential under the 15,20 , and $25^{\circ} \mathrm{C}$ conditions continued to increase during fruit ripening (Tukey-Kramer test, $P<0.05$; data not shown); the maximum pigmentation potential was found in the $15{ }^{\circ} \mathrm{C}$ treatment at harvest $\left(24.4 \mu \mathrm{g} \cdot \mathrm{cm}^{-2}\right)$ (Fig. 1D). The final anthocyanin concentration in the attached fruit of 'Akibae' was $135.6 \mu \mathrm{g} \cdot \mathrm{cm}^{-2}$, which was the highest among the four cultivars examined.
The temperature dependency of anthocyanin accumulation in fruit skin differed among the cultivars, and the interaction between cultivar and time point was significant with respect to the temperature treatment over 3 years $(P<0.001)$. However, in the detached fruit of each cultivar, $15^{\circ} \mathrm{C}$ was generally the optimal temperature for anthocyanin development during fruit ripening, whereas the increase in anthocyanin accumulation was repressed under the $30{ }^{\circ} \mathrm{C}$ treatment at all times, indicating that $30^{\circ} \mathrm{C}$ was too high for anthocyanin synthesis in these apple cultivars. Therefore, we concluded that comparisons of pigmentation potential in the 15 and $25^{\circ} \mathrm{C}$ treatments were effective for estimating anthocyanin accumulation in fruit skin under hotter climatic conditions in an early-maturing cultivar and in a medium-maturing cultivar that was harvested early.

Ethylene production during temperature treatment in detached apples. The ethylene 
production rates in the four cultivars were measured in 2009 before and after the 15 and $25^{\circ} \mathrm{C}$ treatments at the same time points as in Figure 1. Ethylene production in the fruits of 'Tsugaru' and 'Tsugaru Hime' at 4 WBH was below the detectable level before and after temperature treatment (Fig. 2A and B). The fruit began to produce ethylene at $2 \mathrm{WBH}$ [up to 1.4 and $0.5 \mathrm{nl} \cdot \mathrm{g}^{-1}$ fresh weight $(\mathrm{FW}) / \mathrm{h}$ in 'Tsugaru' and 'Tsugaru Hime', respectively]. 'Tsugaru' fruit at harvest produced a large amount of ethylene $\left(89.6 \mathrm{nl} \cdot \mathrm{g}^{-1} \mathrm{FW} / \mathrm{h}\right)$; this increased significantly to 162.5 and 216.1 $\mathrm{nl} \cdot \mathrm{g}^{-1} \mathrm{FW} / \mathrm{h}$ after the 15 and $25^{\circ} \mathrm{C}$ treatments, respectively. 'Tsugaru Hime' fruit at harvest produced ethylene at a rate of $38.3 \mathrm{nl} \cdot \mathrm{g}^{-1}$ $\mathrm{FW} / \mathrm{h}$ before temperature treatment and there was no significant difference between before and after the treatments at harvest, although the average rates increased after temperature treatment.
The fruits of 'Akane' and 'Akibae' produced considerably lower levels of ethylene compared with those of 'Tsugaru' and 'Tsugaru Hime' during the experimental period (Fig. 2C and D). The interaction between cultivar and time point on ethylene production in detached fruit before temperature treatment was significant $(P<0.001)$, indicating that the rate of ethylene production varied among the cultivars. At $4 \mathrm{WBH}$, 'Akane' fruit produced ethylene at a rate of $0.5 \mathrm{nl} \cdot \mathrm{g}^{-1} \mathrm{FW} / \mathrm{h}$, whereas ethylene production was below the detectable level in 'Akibae' fruit. In 'Akane', the ethylene level did not vary substantially during temperature treatment at any time point. 'Akibae' fruit at 2 WBH produced ethylene at a rate of $1.8 \mathrm{nl} \cdot \mathrm{g}^{-1}$ $\mathrm{FW} / \mathrm{h}$, and it did not change during temperature treatment. At harvest, the ethylene production rate in 'Akibae' fruit increased after $25{ }^{\circ} \mathrm{C}$ treatment, but not after treatment at $15^{\circ} \mathrm{C}$. The effect of bagging on ethylene production was
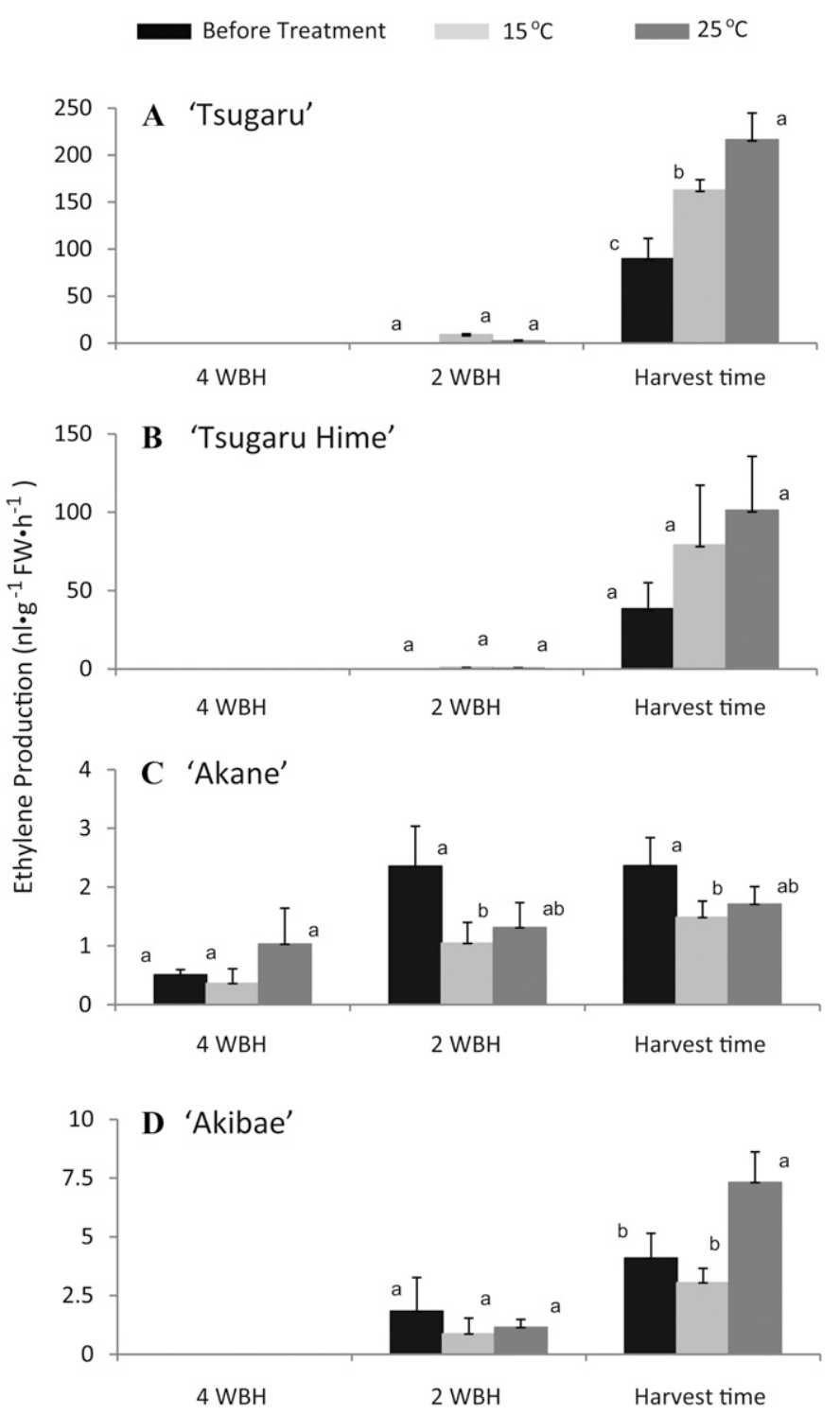

Fig. 2. The rate of ethylene production in detached fruits before and after temperature treatment Temperature treatments were conducted in 2009 by maintaining detached fruits at 15 or $25^{\circ} \mathrm{C}$ for $48 \mathrm{~h}$ : (A) 'Tsugaru', (B) 'Tsugaru Hime', (C) 'Akane', and (D) 'Akibae'. Each bar represents the mean of six replicates; error bars indicate \pm 1 SE. Error bars are not shown when the SE was smaller than the column. Different letters indicate significant differences between temperature treatments within the same day at $P<0.01$, as determined using Tukey-Kramer tests. not found in the four cultivars at any point (data not shown).

Effect of the postharvest application of 1-MCP on ethylene production and anthocyanin accumulation in detached apples. The rate of ethylene production in fruit with or without 1-MCP application was measured after harvest using detached fruit of each cultivar in 2011 (Fig. 3A). The application of 1-MCP repressed ethylene production in 'Tsugaru' fruit, as reported by Tatsuki et al. (2011). The rate of ethylene production in the 1-MCP-treated fruit decreased from 144.5 to $14.0 \mathrm{nl} \cdot \mathrm{g}^{-1} \mathrm{FW} / \mathrm{h}$ at $4 \mathrm{DAH}$. Suppression of ethylene production by 1-MCP application was also evident in the 'Tsugaru Hime' fruit. The rate in the 1-MCP-treated 'Tsugaru Hime' fruit decreased from 50.1 to $1.0 \mathrm{nl} \cdot \mathrm{g}^{-1} \mathrm{FW} / \mathrm{h}$ at 4 DAH. In contrast, 1-MCP application did not affect ethylene production by 'Akane' or 'Akibae' apples. The rate of ethylene production by the 1-MCP-untreated 'Akane' and 'Akibae' fruits at harvest was 0.8 and 0.3 $\mathrm{nl} \cdot \mathrm{g}^{-1} \mathrm{FW} / \mathrm{h}$, respectively; ethylene production by 1-MCP-untreated and -treated fruits of both cultivars remained unchanged until $4 \mathrm{DAH}$

The temperature treatment of 1-MCPuntreated and -treated fruits began at $2 \mathrm{DAH}$, and the anthocyanin concentration in the skin of the fruit was measured at 4 DAH (Fig. 3B). In 'Tsugaru' and 'Tsugaru Hime', the increase in anthocyanin concentration in fruit skin after temperature treatment was repressed by $1-\mathrm{MCP}$ application. However, after the $15{ }^{\circ} \mathrm{C}$ treatment, there was no significant difference in anthocyanin concentration between fruits treated with and without 1-MCP application in 'Tsugaru'. In 'Akane', after both temperature treatments, there was no significant difference in anthocyanin concentration between fruits treated with and without 1-MCP. In 'Akibae', the anthocyanin concentration in the 1-MCPtreated fruits was significantly lower than that in the 1-MCP-untreated fruit after the $15{ }^{\circ} \mathrm{C}$ treatment. After the $25{ }^{\circ} \mathrm{C}$ treatment, the concentration of anthocyanin increased to 7.3 and $5.6 \mu \mathrm{g} \cdot \mathrm{cm}^{-2}$ in the 1-MCP-untreated and -treated fruits, respectively; however, this difference was not significant. Thus, the inhibition of ethylene action by 1-MCP application suppressed anthocyanin accumulation in the fruits of 'Tsugaru', 'Tsugaru Hime', and 'Akibae', but not in 'Akane' fruit.

Effect of temperature on anthocyanin accumulation in attached fruit from potted trees. Potted trees of 'Misuzu Tsugaru', another red sport of 'Tsugaru', were used to investigate the effects of different climatic conditions on anthocyanin accumulation in attached apple fruit. The change in temperature in the field from July to September in 2009 followed the normal course, although the minimum temperature from late August to mid-September was lower than normal (Fig. 4A). Two greenhouses were used to create control $\left(25^{\circ} \mathrm{C} 12 \mathrm{~h} / 15^{\circ} \mathrm{C} 12 \mathrm{~h}\right)$ and hotter climatic conditions $\left(29^{\circ} \mathrm{C} 12 \mathrm{~h} / 19^{\circ} \mathrm{C}\right.$ $12 \mathrm{~h})$. The changes in ambient temperature in the greenhouses over 1 week during the experimental period ( 8 to 15 Sept.) are shown in Figure 4B. 
A

Ethylene
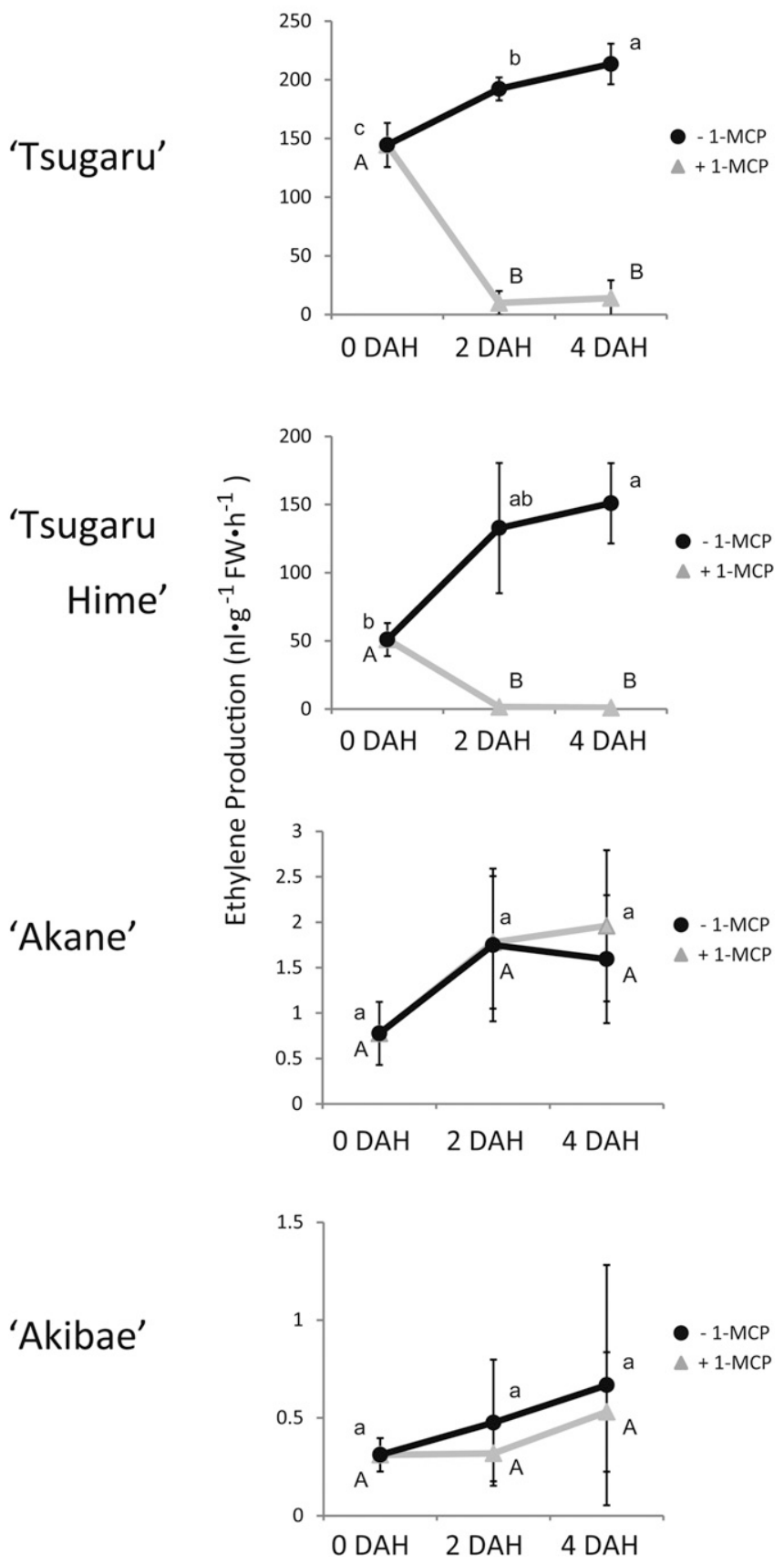

B

Anthocyanin
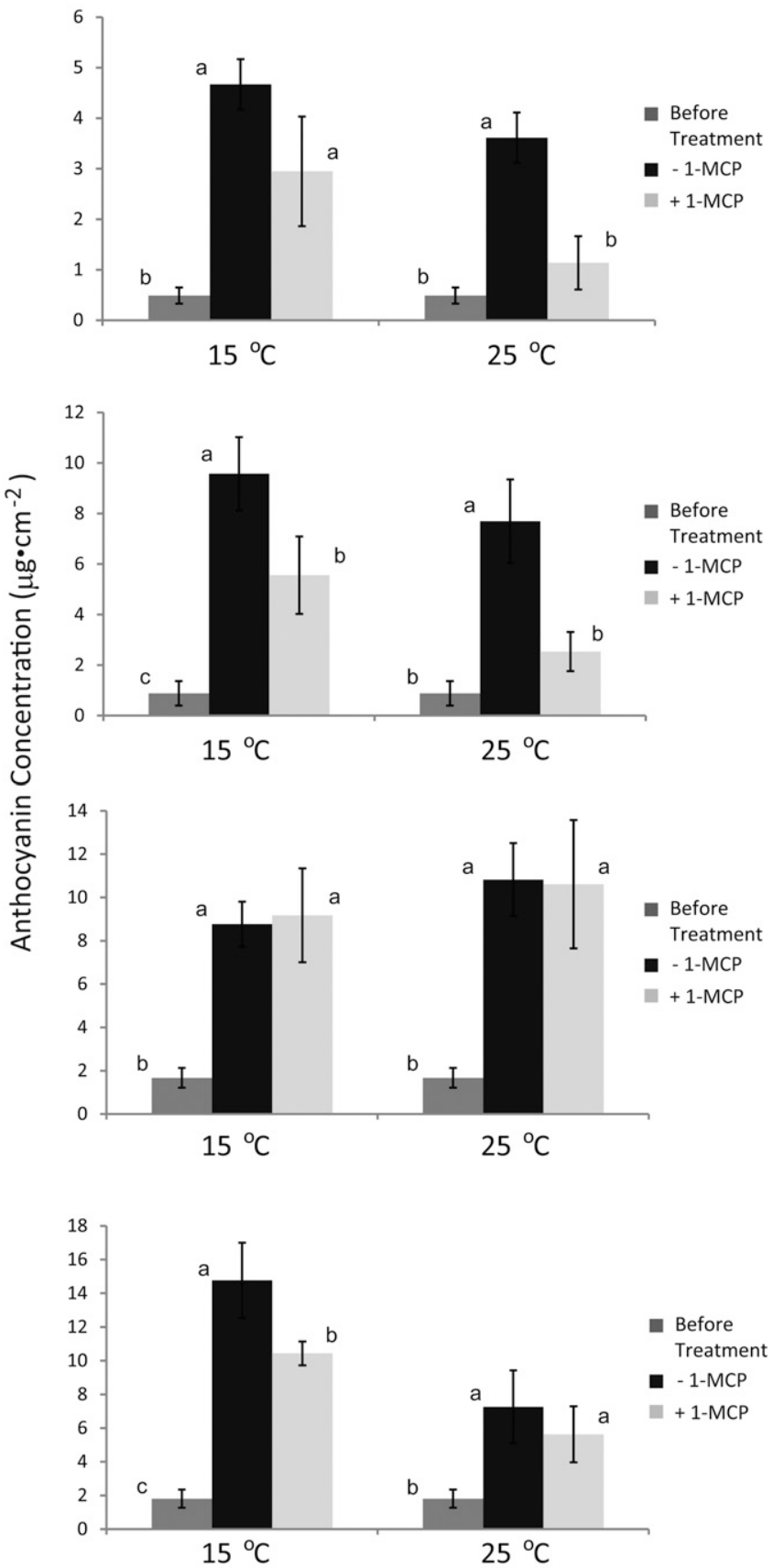

Fig. 3. Effect of 1-methylcyclopropene (1-MCP) application on ethylene production and anthocyanin biosynthesis in detached apple fruits of 'Tsugaru', 'Tsugaru Hime', 'Akane', and 'Akibae'. (A) The rate of ethylene production in apple fruits with or without 1-MCP application in 2011, and (B) the anthocyanin concentration in fruit skins after temperature treatment $\left(15\right.$ or $25^{\circ} \mathrm{C}$ for $\left.48 \mathrm{~h}\right)$ with or without 1-MCP application. Each symbol or bar represents the mean of six to 10 replicates; error bars indicate \pm 1 SE. In (A), error bars are not shown when the SE was smaller than the symbol and different letters indicate a significant difference between time points under the same experimental conditions at $P<0.01$, as determined using Tukey-Kramer tests. In (B), different letters indicate a significant difference with and without 1-MCP application under the same temperature condition at $P<0.01$, as determined using Tukey-Kramer tests.

The anthocyanin concentrations in fruits from potted trees in the field and under control and hotter climatic conditions were measured at four time points during fruit ripening (Fig. 4C). In the field, anthocyanin accumulation in the fruit skin continued to increase throughout the experiment; the anthocyanin concentration at harvest was 45.2 $\mu \mathrm{g} \cdot \mathrm{cm}^{-2}$. In the potted trees from the two greenhouses, anthocyanin development in the fruit skin began later; in the control treatment, anthocyanin accumulation began between 1 and $3 \mathrm{WBH}$, and under the hotter climatic condition, anthocyanin accumulation began during the final week of the experiment. The final anthocyanin concentrations in fruits from trees subjected to the control and hotter climatic conditions were 26.8 and $19.0 \mu \mathrm{g} \cdot \mathrm{cm}^{-2}$, respectively. The rates of increase in anthocyanin concentration in the field, control greenhouse, and hotter greenhouse during the final week of the study were $2.5,2.1$, and $1.9 \mu \mathrm{g} \cdot \mathrm{cm}^{-2} \cdot \mathrm{d}^{-1}$, respectively.
Ethylene production in fruits from the potted trees varied markedly (Fig. 4D-F) and the rate under field conditions at harvest was considerably lower in contrast to 'Tsugaru' and 'Tsugaru Hime' fruits from trees planted in the ground (Fig. 2A and B). In fruits from potted trees in the field, ethylene production remained under the detectable level until $1 \mathrm{WBH}$, and several fruits produced ethylene at harvest (up to $1.0 \mathrm{nl} \cdot \mathrm{g}^{-1}$ $\mathrm{FW} / \mathrm{h}$ ). With respect to trees subjected to control and hotter climatic conditions, more 
A

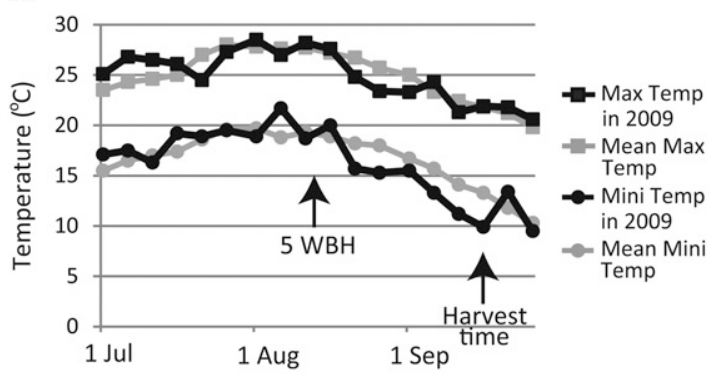

B

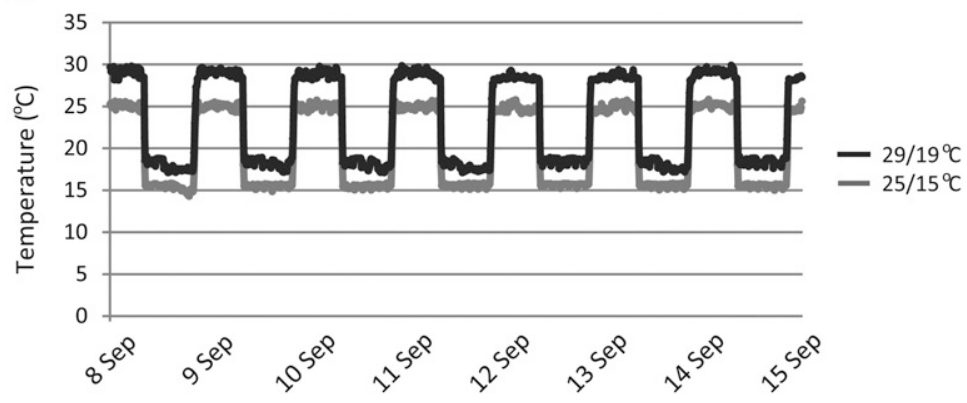

C

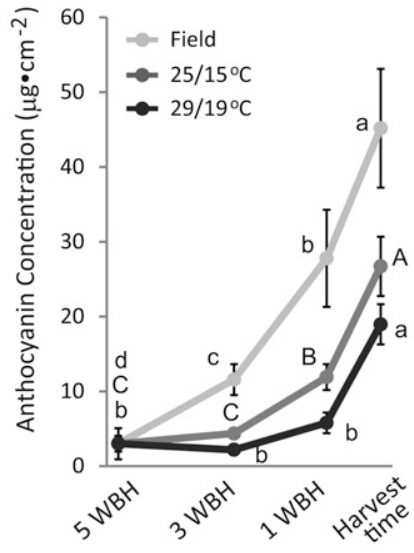

D



E

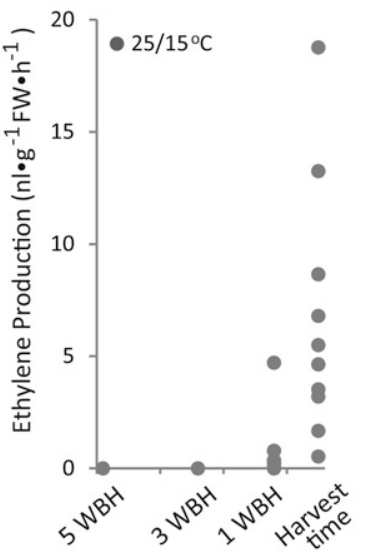

F

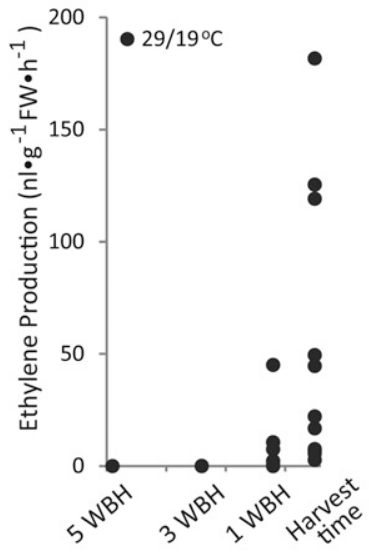

G

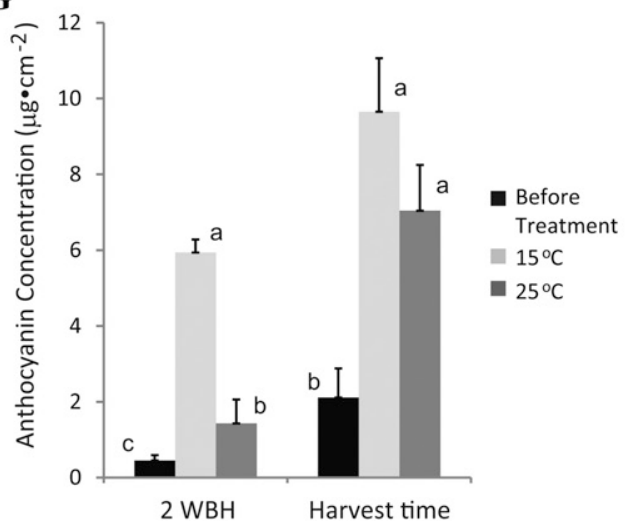

Fig. 4. Changes in anthocyanin accumulation and ethylene production in 'Misuzu Tsugaru' fruit under different temperature conditions. (A) Changes in temperature in the field from July to September in 2009, (B) ambient temperatures of the two greenhouses during a 1-week period, (C) anthocyanin development in attached fruits under field, control, and hotter climatic conditions, (D) the rate of ethylene production in the field, (E) the rate of ethylene production under control conditions, (F) the rate of ethylene production under hotter climatic conditions, and (G) the effect of temperature treatment (15 or $25^{\circ} \mathrm{C}$ ) on the induction of anthocyanin synthesis in detached fruit of 'Misuzu Tsugaru' during the ripening period. (A) Average 5-d maximum and minimum temperatures in 2009 (black square and circle) and mean maximum and minimum temperatures (gray square and circle). (C) Each symbol represents the mean of 10 to 12 samples from two single-tree replicates; error bars indicate $\pm 1 \mathrm{sE}$. Different letters indicate a significant difference between time points under the same temperature condition at $P<0.01$, as determined using Tukey-Kramer tests. (D-F) Each symbol represents a single value; measurements were obtained from 10 to 12 samples from two single-tree replicates. In $(\mathbf{G})$ different letters indicate significant differences between temperature treatments within the same day at $P<0.01$, as determined using Tukey-Kramer tests.

than half of the fruit began to produce ethylene at $1 \mathrm{WBH}$, and the rates of production peaked at 18.8 and $181.7 \mathrm{nl} \cdot \mathrm{g}^{-1}$ $\mathrm{FW} / \mathrm{h}$, respectively, at harvest. The quality of the fruit from the potted trees (excluding fruit firmness) was similar to those of 'Tsugaru' at commercial harvest (Table 1). Fruit firmness in the potted trees grown under field, control, and hotter climatic conditions was found to be $76.4,66.4$, and $70.4 \mathrm{~N}$, respec- tively. Because there were no differences in fruit firmness among the three conditions, the high fruit firmness was likely the result of growing the trees in a pot.

In addition, the anthocyanin concentration after the 15 and $25^{\circ} \mathrm{C}$ treatments was measured in 2011 in 'Misuzu Tsugaru' fruit detached from trees planted in the ground using the same method as in Figure 1. The pigmentation potential under the 15 and $25^{\circ} \mathrm{C}$ treatments was found at $2 \mathrm{WBH}$ and at harvest (Fig. 4G); moreover, the pattern was similar to that in 'Tsugaru' and 'Tsugaru Hime' (Fig. 1A and B). After the $15^{\circ} \mathrm{C}$ treatment, the anthocyanin concentration was higher than that after the $25^{\circ} \mathrm{C}$ treatment at $2 \mathrm{WBH}$; in comparison, there was no significant difference between the treatments at harvest. Therefore, anthocyanin accumulation in the skin of 'Misuzu Tsugaru' fruit at 
harvest proceeded at a relatively high temperature $\left(25^{\circ} \mathrm{C}\right)$.

\section{Discussion}

We investigated the pigmentation potential for anthocyanin synthesis in fruit skins during ripening using detached fruit of four cultivars and found that the temperature dependency of anthocyanin accumulation differed among the cultivars, particularly for the $25{ }^{\circ} \mathrm{C}$ treatment (Fig. 1). Because 'Tsugaru Hime' was a red sport of 'Tsugaru', they showed a similar pattern in which the pigmentation potential in the $25{ }^{\circ} \mathrm{C}$ treatment increased at harvest compared with that at 2 WBH. The potential of 'Akane' in the $25^{\circ} \mathrm{C}$ treated fruit reached the same level as in the $15{ }^{\circ} \mathrm{C}$ treated fruit at $2 \mathrm{WBH}$. These results indicate that in these cultivars, anthocyanin accumulation proceeded under hotter conditions toward harvest. Lowertemperature treatment induced greater anthocyanin accumulation in 'Akibae' fruit up to the time of harvest, similar to 'Tsugaru' and 'Tsugaru Hime'. In 'Akibae', the pigmentation potential at harvest after the $25^{\circ} \mathrm{C}$ treatment $\left(15.3 \mu \mathrm{g} \cdot \mathrm{cm}^{-2}\right)$ was the highest among the four cultivars. This trait of 'Akibae' would give rise to high anthocyanin concentrations in the skin of attached fruit at harvest.

The effect of the inhibition of ethylene action by 1-MCP application on ethylene production and anthocyanin accumulation differed among the cultivars (Fig. 3). The 1-MCP-treated fruits of 'Tsugaru' and 'Tsugaru Hime' showed a similar response; ethylene production and anthocyanin accumulation were repressed after the application of 1-MCP. In contrast, the inhibition of ethylene action by 1-MCP application did not affect either ethylene production or anthocyanin production in 'Akane' fruit at harvest. In the 1-MCP-treated fruit of 'Akibae', ethylene production remained unchanged, but anthocyanin synthesis in the $15{ }^{\circ} \mathrm{C}$ treatment was repressed. Blankenship and Dole (2003) assumed that 1-MCP binds irreversibly to ethylene receptors present at the time of treatment and that any recovery of ethylene sensitivity is the result of the appearance of a new site. In apple, six ethylene receptor genes (MdETR1, MdETR1b, MdETR2, MdETR5, MdERS1, and MdERS2) have been isolated (Dal Cin et al., 2005; Tatsuki and Endo, 2006; Wiersma et al., 2007), but the rate of turnover of the receptors and the duration of the inhibitory effect by 1-MCP-bound receptors remain unknown (Tatsuki et al., 2007). Therefore, variations in the response to 1-MCP application may reflect differences in ethylene receptor characteristics between cultivars.

Lin-Wang et al. (2011) and Palmer et al. (2012) compared changes in the anthocyanin concentration of 'Royal Gala' fruit from trees grown in a region with moderate summer temperatures in New Zealand and in a region with high summer temperatures in Spain. They demonstrated that anthocyanin accumulation in fruit from the trees grown in Spain was suppressed to one-fourth compared with that in fruit from New Zealand. They also conducted orchard-based apple heating experiments using 'Royal Gala' trees and demonstrated that the maintenance of fruit skin temperatures above $20{ }^{\circ} \mathrm{C}$ for a $7-\mathrm{d}$ period, starting $11 \mathrm{~d}$ before harvest, inhibited increases in the anthocyanin concentration in fruit skin. Moreover, it has been reported that a decrease in orchard temperature improved the color of apple fruit (Iglesias et al., 2002, 2005), clearly indicating the effect of temperature on anthocyanin biosynthesis in apple fruit skin. We obtained a similar result; the anthocyanin concentration in 'Misuzu Tsugaru' fruit from potted trees grown at a hotter climate for 5 weeks was lower than that in fruit grown under control conditions (Fig. 4C). Nevertheless, the rate of increase in anthocyanin concentration in the hotter climate was elevated from 0.3 to 1.9 $\mu \mathrm{g} \cdot \mathrm{cm}^{-2} \cdot \mathrm{d}^{-1}$ at $1 \mathrm{WBH}$. The increased rate during the last week in the hotter climate reached a level that was close to that under control conditions $\left(2.1 \mu \mathrm{g} \cdot \mathrm{cm}^{-2} \cdot \mathrm{d}^{-1}\right)$. This result was supported by the finding that detached fruit of 'Misuzu Tsugaru' at harvest accumulated identical anthocyanin levels after the 25 and $15{ }^{\circ} \mathrm{C}$ treatments, unlike the findings at 2 WBH (Fig. 4G).

Although the rates of ethylene production varied, 'Misuzu Tsugaru' fruit sampled from potted trees after the hotter climatic treatment produced ethylene at up to $181.7 \mathrm{nl} \cdot \mathrm{g}^{-1} \mathrm{FW} / \mathrm{h}$, which was 9-fold higher than under the control condition at harvest (Fig. 4E and F). This indicates that 'Misuzu Tsugaru' fruit grown under hotter climatic conditions during ripening produced a larger amount of ethylene after harvest. The development of red color proceeded in 'Misuzu Tsugaru' attached fruit from the potted trees in the field, although ethylene production was below the detectable level (Fig. 4C and D), suggesting that in 'Misuzu Tsugaru', the ethylene action required for pigmentation in the fruit skin is activated by a small amount of ethylene. Arakawa et al. (1985) demonstrated that the application of aminoethoxyvinylglycine, an inhibitor of ethylene synthesis, decreased ethylene production but had little effect on anthocyanin development in ultraviolet-B-irradiated 'Jonathan' fruit. Our speculation appears to support not only their report, but also our results in Figures 1 and 2 . The final anthocyanin concentrations in attached fruits of 'Akane' and 'Akibae' were higher than those in attached fruits of 'Tsugaru' and 'Tsugaru Hime', whereas the ethylene levels in the former cultivars were considerably lower than those in the latter cultivars at harvest (Figs. 1 and 2A). In the former cultivars, a relatively lower amount of ethylene may be enough for inducing ethylene action to synthesize anthocyanin in fruit skin at harvest. Moreover, it is possible that the increase in ethylene in detached 'Tsugaru' fruit at harvest (Fig. 2A) did not contribute to the effect of ethylene on anthocyanin accumulation under 15 or $25^{\circ} \mathrm{C}$ treatment (Fig. 1A).
In conclusion, comparisons of pigmentation potential after treatment at 15 and $25{ }^{\circ} \mathrm{C}$ in detached fruit were effective for estimating anthocyanin accumulation in fruit skin under hotter climatic conditions in early- and mediummaturing cultivars that were harvested early because the response of anthocyanin development in attached fruit of potted trees of 'Misuzu Tsugaru' to hotter climatic conditions during ripening was similar to the results using detached fruit. Our experiment using potted trees of 'Misuzu Tsugaru' in a greenhouse indicates that exposure to the hotter condition during ripening increased ethylene production in the fruit after harvest.

\section{Literature Cited}

Arakawa, O. 1991. Effect of temperature on anthocyanin accumulation in apple fruit as affected by cultivar, stage of fruit ripening and bagging. J. Hort. Sci. 66:763-768.

Arakawa, O., Y. Hori, and R. Ogata. 1985. Relative effectiveness and interaction of ultraviolet-B, red and blue light in anthocyanin synthesis of apple fruit. Physiol. Plant. 34:323-327.

Ban, Y., C. Honda, Y. Hatsuyama, M. Igarashi, H. Bessho, and T. Moriguchi. 2007. Isolation and functional analysis of a MYB transcription factor gene that is a key regulator for the development of red coloration in apple skin. Plant Cell Physiol. 48:958-970.

Blankenship, S.M. and J.M. Dole. 2003. 1-methylcyclopropene: A review. Postharvest Biol. Technol. 28:1-25.

Chalmers, D.J., J.D. Faragher, and J.W. Raff. 1973. Changes in anthocyanin synthesis as an index of maturity in red apple varieties. J. Hort. Sci. 48:378-392.

Curry, E.A. 1997. Temperature for optimum anthocyanin accumulation in apple tissue. J. Hort. Sci. 72:723-729.

Dal Cin, V., M. Danesin, A. Boshetti, A. Dorigoni, and A. Ramina. 2005. Ethylene biosynthesis and perception in apple fruitlet abscission [Malus domestica (L.) Borkh]. J. Expt. Bot. 56:2995-3005.

Elfving, D.C., R.D. Stephen, A.N. Reed, and D.B. Visser. 2007. Preharvest application of sprayable 1-methylcyclopropene in the orchard for management of apple harvest and postharvest conditions. HortScience 42:1192-1199.

Faragher, J.D. 1983. Temperature regulation of anthocyanin accumulation in apple skin. J. Expt. Bot. 34:1291-1298.

Hua, L. and E.M. Meyerowitz. 1998. Ethylene responses are negatively regulated by a receptor gene family in Arabidopsis thaliana. Cell 94:261-271

Iglesias, I. and G. Echeverría. 2009. Does strain affect fruit color development, anthocyanin content and fruit quality in 'Gala' apples? A comparative study over three seasons. J. Amer. Pomol. Soc. 63:168-180.

Iglesias, I., G. Echeverría, and M.L. Lopez. 2012. Fruit color development, anthocyanin content, standard quality, volatile compound emissions and consumer acceptability of several 'Fuji' apple strains. Sci. Hort. 137:138-147.

Iglesias, I., J. Graell, G. Echeverría, and M. Vendrell. 1999a. Differences in fruit colour development, anthocyanin content, yield and quality of seven 'Delicious' apple strains. Fruit Var. J. 53:133-145.

Iglesias, I., J. Graell, D. Faro, C. Larrigaudiere, I. Recasens, G. Echeverría, and M. Vendrell. 1999b. Efecto del sistema de riego en la 
coloración de los frutos, contenido de antocianos y actividad de la fenilalanina amonioliasa (PAL), en la variedad de manzana 'Starking Delicious'. Investigación Agraria Producción y Protección Vegetal 14:157-172.

Iglesias, I., J. Salvía, L. Torguet, and C. Cabús. 2002. Orchard cooling with overtree microsprinkler irrigation to improve fruit colour and quality of 'Topred Delicious' apples. Sci. Hort. 93:39-51.

Iglesias, I., J. Salvia, L. Torguet, and R. Montserrat. 2005. The evaporative cooling effects of overtree microsprinkler irrigation on 'Mondial Gala' apples. Sci. Hort. 103:267-287.

Johnston, J.W., K. Gunaseelan, P. Pidakala, M. Wang, and R.J. Schaffer. 2009. Co-ordination of early and late ripening events in apples is regulated though differential sensitivities to ethylene. J. Expt. Bot. 60:2689-2699.

Larrigaudiere, C., E. Pinto, and M. Vendrell. 1996. Differential effects of ethephon and seniphos on color development of 'Starking Delicious' apple. J. Amer. Soc. Hort. Sci. 121:746-750.

Li, Z., H. Gemma, and S. Iwahori. 2002. Simulation of 'Fuji' apple skin color by ethephon and phosphorus-calcium mixed compounds in relation to flavonoid synthesis. Sci. Hort. 94: 193-199.

Lin-Wang, K., D. Micheletti, J. Palmer, R. Volz, L. Lozano, R. Espley, R.P. Hellens, D. Chagnè, D.D. Rowan, M. Troggio, I. Iglesias, and A.C. Allan. 2011. High temperature reduces apple fruit colour via modulation of the anthocyanin regulatory complex. Plant Cell Environ. 34 1176-1190.

Marais, E., G. Jacobs, and D.M. Holcroft. 2001. Light and temperature affect postharvest colour development in 'Cripps Pink' apples. Acta Hort. 553:91-93.

Palmer, J., L. Lozano, D. Chagné, R. Volz, K. LinWang, J. Bonany, D. Micheletti, M. Troggio, A. White, S. Kumar, A.C. Allan, and I. Iglesias. 2012. Physiological, molecular and genetic control of apple skin colouration under hot temperature environments. In: Litz RE (ed.) Proc. XXVIII ${ }^{\text {th }}$ IHC-IS on Genomics and Genetic Transformation of Horticultural Crops. Acta Hort. 929:81-87.

Saure, M.C. 1990. External control of anthocyanin formation in apple. Sci. Hort. 42:181-218.

Soejima, J., H. Bessho, S. Tsuchiya, S. Komori, K. Abe, and N. Kotoda. 1998. Breeding of Fuji apples and performance on JM rootstocks. Compact Fruit Tree 31:22-24.

Tatsuki, M. and A. Endo. 2006. Analysis of expression patterns of ethylene receptor genes in apple (Malus domestica Borkh.) fruit treated with or without 1-methylcyclopropene (1-MCP). J. Jpn. Soc. Hort. Sci. 75:481-487.

Tatsuki, M., A. Endo, and H. Ohkawa. 2007. Influence of time from harvest to 1-MCP treatment on apple fruit quality and expression of genes for ethylene biosynthesis enzymes and ethylene receptors. Postharvest Biol. Technol. 43:28-35.
Tatsuki, M., H. Hayama, H. Yoshioka, and Y. Nakamura. 2011. Cold pre-treatment is effective for 1-MCP efficacy in 'Tsugaru' apple fruit. Postharvest Biol. Technol. 62: 282-287.

Tromp, J. 1997. Maturity of apple cv. Elstar as affected by temperature during a six week period following bloom. J. Hort. Sci. 72:811819.

Ubi, B.E. 2004. External stimulation of anthocyanin biosynthesis in apple fruit. Food Agr. Environ. 2:65-70

Ubi, B.E., C. Honda, H. Bessho, S. Kondo, M. Wada, S. Kobayashi, and T. Moriguchi. 2006. Expression of anthocyanin biosynthetic genes in apple skin: Effect of UV-B and temperature. Plant Sci. 170:571-578.

Whale, S.K. and Z. Singh. 2007. Endogenous ethylene and color development in the skin of 'Pink Lady' apple. J. Amer. Soc. Hort. Sci. 132:20-28.

Wiersma, P.A., H. Zhang, C. Lu, A. Quail, and P.M.A. Toivonen. 2007. Survey of the expression of genes for ethylene synthesis and perception during maturation and ripening of 'Sunrise' and 'Golden Delicious' apple fruit. Postharvest Biol. Technol. 44:204 211.

Yuan, R. and J. Li. 2008. Effect of sprayable 1-MCP, AVG, and NAA on ethylene biosynthesis, preharvest fruit drop, fruit maturity, and quality of 'Delicious' apples. HortScience 43:1454-1460. 